\title{
Bioindicators in Radiation Protection
}

\author{
Ademir Amaral*, Thiago Salazar Fernandes and Mariana Brayner Cavalcanti \\ Grupo de Estudos em Radioproteção e Radioecologia; Departamento de Energia Nuclear; Universidade Federal de \\ Pernambuco; Av. Professor Luiz Freire, 1000; 50740540; amaral@.ufpe.br; Recife - PE - Brasil
}

\begin{abstract}
Biodosimetry is the evaluation of absorbed dose using bioindicators. Among chromosomal aberrations, scoring of dicentrics from peripheral human blood has been used as gold standard for biodosimetry, although in case of large scale incidents its use presents some drawbacks. Advances in technology have led to new investigations allowing or permitting the use of new methods which not only improve this "classical" biodosimetry but permits the design of other bioindicators making possible faster analyses, particularly in events where many persons may have been exposed. This report presents an overview of some recent studies developed by the "Grupo de Estudos em Radioproteção e Radioecologia - GERAR”, Nuclear Energy Department of UFPE - Brazil, involving biodosimetry.
\end{abstract}

Key words: Biodosimetry, Physical Dosimetry, Radioprotection, Bioindicators, Protein expression

\section{INTRODUCTION}

The discovery of ionizing radiations (IR) may be considered as a watershed in human history for improving the quality of life, especially as an important tool in medicine and as source of energy. However, the initial lack of knowledge about the physical, chemical and biological phenomena involved in the interactions of IR with living tissues was responsible for deaths among the pioneering radiation workers and exposed patients (Kathren, 1962; Caufield, 1990). Since then, radiation protection (radioprotection) was introduced as the science in charge of protecting people (workers or not) and the environment from the harmful effects of radiation. Radioprotection has been continuously reviewed, and well documented in detail over the years. The importance of radiation protection programs has grown due to the increase in the application of ionizing radiation as much as because of the public interest on potential risks associated with radiation. Up today, radioprotection management is based on the evaluation of specific dosimetric quantities. Absorbed dose, the amount of energy delivered to matter by IR per unit of mass, is the fundamental physical quantity to evaluate potential biological response resulting from exposure to radiation. Although for the International System of Units, the unit of absorbed dose is the gray (1 Gy $=1 \mathrm{~J} . \mathrm{kg}-1)($ ICRP, 1991), the rad unit $(1 \mathrm{rad}=0,01$ $\mathrm{Gy}=1 \mathrm{cGy}$ ) is commonly used principally when medical radiology is performed.

In general, absorbed dose can be directly determined by physical dosimeters (such as film or TLD badges, semiconductors, ionization chambers) or, indirectly, by numerical models. However, in most cases of real or suspected accidental exposures to IR, physical dosimetry cannot be straightforwardly performed for retrospective estimates, mainly due to the lack of information about the irradiation conditions.

\footnotetext{
* Author for correspondence
} 
In such situations, biological dosimetry (biodosimetry) has been proposed as an alternative method, which is based on the investigation of cellular and molecular changes (bioindicators) induced by IR, in order to correlate them with the radiation dose.

In terms of radioprotection, bioindicators can be defined as all individual biological endpoints (macro- or microscopic changes) used to indicate an exposure to IR, principally, representing an early event that occurs as a result of IR interaction with living tissues (Bonassi and $\mathrm{Au}, 2002$ ).

\section{First Bioindicators: Physical Symptoms}

The first observed bioindicators were the early physical symptoms resulting from individual exposure to ionizing radiation, corresponding to the prodromal stage following an acute irradiation, such as nausea, vomiting, and diarrhea. The severity and duration of those symptoms are related to the absorbed dose and physical characteristics of the radiation, since equal absorbed doses from different forms of radiations (such as $\mathrm{X}$ and $\mathrm{g}$ rays; electrons, protons neutrons and $\alpha$ particles) do not imply the same level of biological response. For example, for 1 to $2 \mathrm{~Gy}$ of gamma irradiation, nausea and vomiting appear within $6 \mathrm{~h}$ after exposure (Roman et al., 1997; Lushbaugh et al., 1982). On the other hand, an absorbed dose of $2 \mathrm{~Gy}$, as a result of external skin contamination, without absorption, will certainly not lead to such physical symptoms.

Another important clinical bioindicator is erythema, which also depends of the type of radiation and the skin condition, having a median dose estimate of $6 \mathrm{~Gy}$ for its appearance. All these symptoms are important "macroscopic" bioindicators of acute irradiation.

Although those "visual" symptoms should be considered as part of the radiation history, they are still found as a result of overexposure to ionizing radiation. Fig. 1 shows the result of chronic overexposure of the left hand of a surgeontraumatologist studied in 2004 in Recife (Brazil) (Fernandes, 2006).

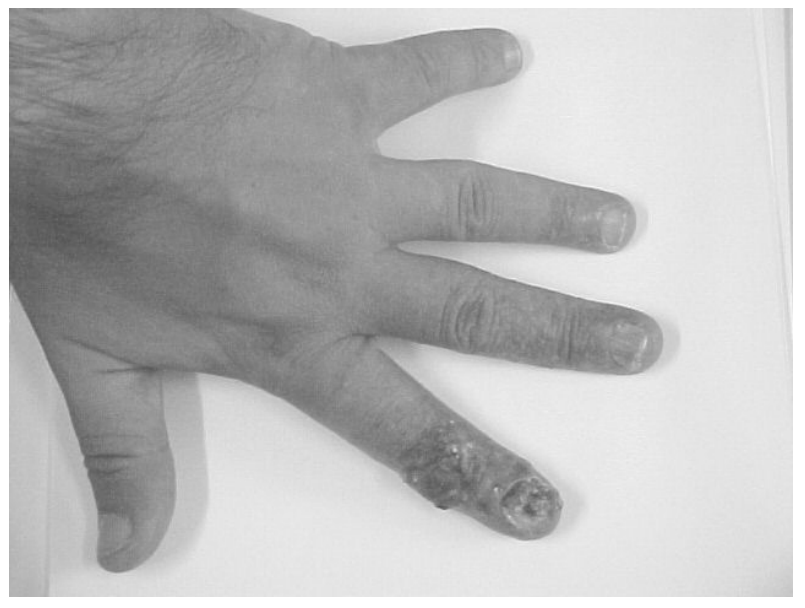

Figure 1 - Left hand of a surgeon traumatolgist presenting an advanced stage of Radiodermatitis

Fig. 1 presents an advanced stage of Radiodermatitis. After deeply biological studies the presence of cancer in the indicator finger was revealed. According to the victim, despite erythema was early observed by his colleagues, including dermatologists, this symptom was associated to an allergic reaction due to the use of surgical gloves rather to radiation overexposure.
Chromosomal Aberrations and Micronulcei

Chromosome aberrations (CA) in circulating lymphocytes of human blood is the most extensively studied system (Bender, 1964; 1969; Lloyd et al., 1986; Lloyd et al., 2000; Amaral, 2005).

Some unstable chromosome-type aberrations (such as dicentrics and rings) are generally considered to be specific to radiation exposure, although in certain circumstances a few chemical agents can also induce them. Several studies have shown no 
significantly differences between in vivo and in vitro CA in irradiated blood lymphocytes (Dossou et al., 2000; IAEA, 2001). Thus, the doseeffect relationship obtained after in vitro irradiation of blood is generally employed as a calibration curve to estimate effects from in vivo irradiations (Ramalho et al., 1995).

Nowadays, two cytogenetic methods have become commonly used: scoring unstable CA (principally dicentrics) and the FISH (fluorescence in situ hybridization), the latter, based on the use of fluorescence probes to visualize dicentrics and translocations without the prerequisite of the timeconsuming karyotyping (Fernandes et al., 2008).

Fig. 2 presents a dicentric evidenced by FISH, making clear the distinction of two centromeres highlighted in red color.

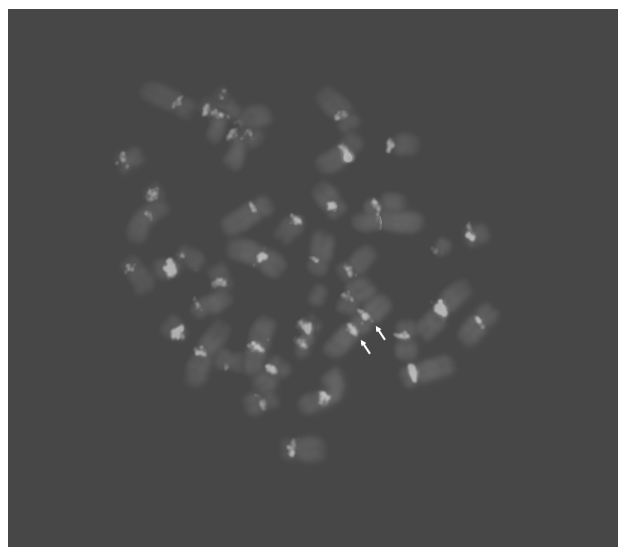

Figure 2 - Metaphase presenting a dicentric (arrows) observed by FISH with two red highlighted centromeres

Works developed by Fernandes et al. (2008) evaluated the relative accuracy of this analysis for unstable chromosomal aberrations in lymphocyte metaphases using four cell staining options, namely: Giemsa; 4 6-Diamidine-2'-phenylindole dihydrochloride (DAPI); C-banding and Centromere Multiplex Fluorescence in situ Hybridization (CM-FISH), these two last techniques highlight centromeres. This study suggests that standard block staining method is the choice for routine sampling because it reduces cost and time for slide preparation. On the other hand, centromere highlighting methods, such FISH, allow a more precise detection of dicentrics and provide confirmation, resolving unequivocal identification of suspected dicentrics.

Dose estimates based on the scoring of chromosome aberrations take into account the uniform whole body irradiation. This is a simple assumption since the majority of accidental or overexposures involve partial-body irradiation, and interpreting the yield in such cases become an outstanding difficulty. In situations such the case of surgeon doctor (Fig. 1), where the overexposure was focused on a very small percentage of the body volume (left hand), cytogenetic studies presented no deviation from background (Fernandes et al., 2006). On the other hand, if a large proportion of the body is overexposed, it is possible to detect dicentrics present in the fraction of lymphocytes from the irradiated part of the body. Fig. 2 presents a dicentric evidenced by FISH, making clear the distinction of two centromeres highlighted in red color (Fernandes et al., 2008).

\section{Micronulei}

Micronuclei (MN) are cytoplasm chromatin, masses that arise from centric or acentric products of damaged chromosomes (Uma Devi et al., 1998; IAEA, 2001). In other words, MN are a kind of unstable CA byproduct. They have the appearance of small nuclei, in addition to the cell's nucleus, as shown in binucleated cells of the Fig. 3, and they are identified during mitogen-activated human lymphocytes division, blocking at cytokinesis stage. As the scoring of $\mathrm{MN}$ is more sensitive and faster than the scoring of $\mathrm{CA}$, improvements in MN methodology for biodosimetry have been tested (IAEA, 2001). As for unstable chromosomal aberration, in order to interpret the scoring of $\mathrm{MN}$ 
in terms of radiation dose, a calibration curve (frequency $\mathrm{MN}$ versus dose) is also necessary.

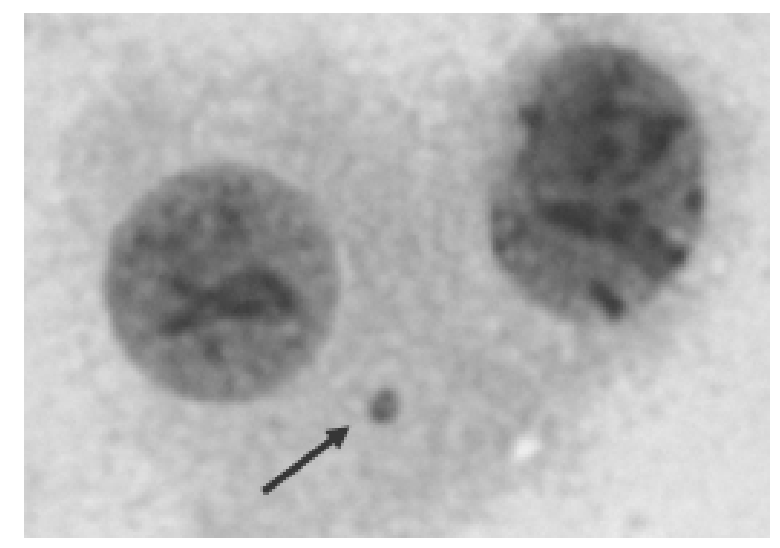

Figure 3 - Binucleated cell containing one micronuclei pointed out by the red arrow.

\section{Measuring Protein Expression}

IR can cause different injuries in DNA, which induce the expression of several proteins in order to repair such damages. Among the proteins expressed during the DNA repair process, $\mathrm{p} 53$ has an important role concerning the genome integrity conservation. This protein is found in the cytoplasm in small concentration and has a short average life. However, a variety of physicochemical agents, after damaging the DNA molecule, trigger the expression of p53 increasing its concentration and its average half-life,making possible its detection (Levine, 1997; Rössner Jr. et al., 2004). Thus, the correlation between the increasing p53 expression and the irradiation may constitute a fast and reliable method of individual monitoring in cases of accidental or suspected exposures to IR.

The advent of fluorescent techniques, particularly flow cytometry, opened new possibilities in terms of detection of intracellular bioindicators. This technique can allow the measurement of multiparameters of cells, such as: size, granularity and complexity (Becton Dickinson and Company, 2000). Hence, Cavalcanti et al. (2008) were the first to propose the evaluation p53 protein expression levels as bioindicator of individual exposure to ionizing radiation by flow cytometry. The authors observed that the p53 expression increased with the absorbed doses.

Using the same methodology described by the authors (Cavalcanti et al., 2008), peripheral blood sample from a healthy donor were exposed to a ${ }^{60} \mathrm{Co}$ source (dose-rate: $196.67 \mathrm{cGy} / \mathrm{min}$ ). Fig. 4 presents the results obtained for two blood samples without irradiation (A), and irradiated with 4 Gy (B), following $72 \mathrm{~h}$ of incubation in a $5 \% \mathrm{CO}_{2}$ at $37^{\circ} \mathrm{C}$ with phytohemagglutinin (PHA). For the non-irradiated sample the p53 expression level (region UL) was $2.76 \%$, while for the irradiated one the percentage of this protein expression was $23.62 \%$. It is possible to verify that the p53 expression levels in samples have increased for all absorbed dose.

The high expression level of p53 in the dot-plot B emphasized the potential of this methodology as screen method to investigate accidental exposures. Obviously, for this, one should keep in mind that individual radiosensitivity plays an important role in this kind of studies. 
UL

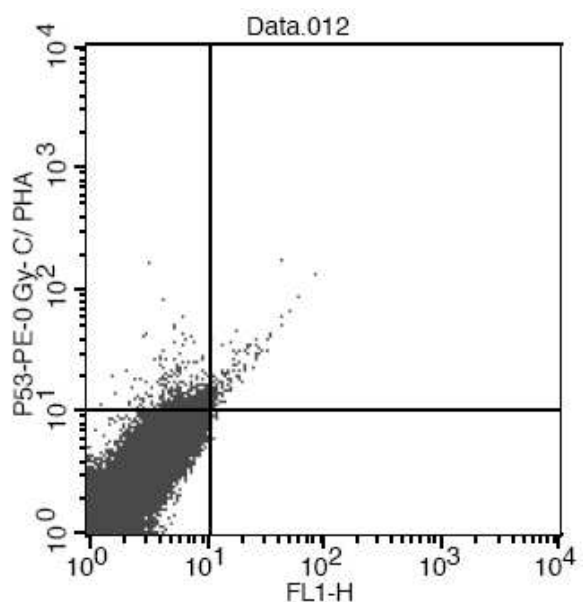

(A)

UL

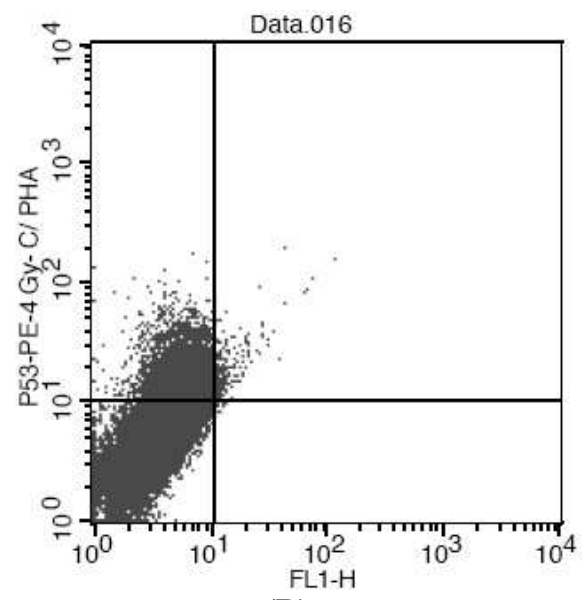

(B)

Figure 4 - Dot-plot from (A) non-irradiated sample and (B) irradiated one with 4 Gy.

\section{CONCLUSION}

In order to evaluate individual irradiation, rapid and reliable dose estimates are crucial for risk assessments. In individual evaluation, biodosimetry may represent more than a complementary methodology to physical dosimetry, especially when this latter is not feasible. Advances in molecular biology together with the appearance of new techniques, such flow cytometry, opened the possibility for correlating intracellular changes with individual absorbed dose.

\section{ACKNOWLEDGMENTS}

The authors are grateful to the Centro de Radioterapia de Pernambuco (CERAPE-Brazil), for providing laboratory facilities, to the Fundação Cooperação de Aperfeiçoamento de Pessoal de Nível Superior (CAPES, Brazil) and Conselho Nacional de Desenvolvimento Científico e Tecnológico (CNPq-Brazil) for financial support.

\section{RESUMO}

Biodosimetria pode ser definida como a avaliação da dose absorvida individualmente usando bioindicadores. Entre as aberrações cromossômicas, a quantificação de discêntricos em sangue periférico humano tem sido usada como padrão ouro in biodosimetria, embora essa técnica possua várias limitações em casos de incidentes envolvendo um grande número de indivíduos. Os avanços tecnológicos têm proporcionado novas 
ferramentas de investigações, resultando no desenvolvimento de novos métodos com intuito de otimizar essa dosimetria biológica "clássica", bem como na descoberta de novos bioindicadores, com o objetivo de possibilitar avaliação de exposição individual de forma mais rápida, em particular em situações envolvendo grande número de indivíduos expostos. Este texto apresenta um breve relato de alguns dos estudos desenvolvidos pelo Grupo de Estudos em Radioproteção e Radioecologia - GERAR, do Departamento de Energia Nuclear da UFPE - Brasil, associados ao emprego dos "clássicos" e novos bioindicadores em biodosimetria.

\section{REFERENCES}

Amaral, A. (2005), Physical and biological dosimetry for risk perception in radioprotection. Braz Arch Biol Technol., 48, Special: 229-234.

Becton Dickinson and Company (2000), Introduction to Flow Cytometry: A learning guide. Manual Part Number, 11, 11032-01.

Bender, M. A. (1964), Chromosome aberrations in irradiated human subjects. Ann NY Acad Sci., 114, 249-125.

Bender, M. A.; Brewen, J. G. (1969), Factors influencing chromosome aberration yields in the human peripheral leukocyte system. Mutat Res., 8, 383-99.

Bonassi, S.; Au, W. W. (2002), Biomarkers in molecular epidemiology studies for health risk prediction. Mutat Res., 511, 73-86.

Cavalcanti, M. B.; Amaral, A. J.; Fernandes, T. S.; Melo, J. A.; Machado, C. G. F. (2008), p53 protein expression levels as bioindicator of individual exposure to ionizing radiation by flow cytometry. Mol Cell Biochem., 308, 127-131.

Caufield, C. (1990), Multiple exposures: chronicles of the radiation. University of Chicago Press, pp 304.

Dossou, J.; Lartigau, E.; M'Kacher, R.; Légal, J-D.; Bridier, A.; Guichard, M.; Eschwege, F.; Parmentier, C. (2000), Biological dosimetry after total body irradiation (TBI) for hematologic malignancy patients. Int. J. Radiation Oncology Biol Phys., 46, 123-129.

Fernandes, T. S.; Amaral, A.; Cavalcanti, M. B.; Braga, L. R.; Melo, R. A. (2006), Unstable chromosome aberrations and micronuclei analyses in the biomonitoring of workers occupationally exposed to ionizing radiation. Int J Low Radiat, 3, 299-309.
Fernandes, T. S.; Lloyd, D. C.; Amaral, A. (2008), A comparison of different cytological stains for biological dosimetry. Int J Radiat Biol., 84, 703-711.

International Atomic Energy Agency - IAEA (2001), Cytogenetic Analysis for Radiation Dose Assessment. Technical Report Series, No. 405, IAEA, Vienna.

International Commission on Radiological Protection ICRP. (1991), Recommendations of the International Commission on Radiological Protection, ICRP-60, Pergamon Press, Oxford.

Kathren, R.L. (1962), Early x-Ray protection in the United States. Health Phys., 8, 503-511.

Levine, A. J. (1997), P53, The cellular gate keeper for growth and division. Cell, 88, 323-331.

Lloyd, D. C.; Edwards, A. A.; Prosser, J. S. (1986), Chromosome Aberrations induced in human lymphocytes by in vitro acute $\mathrm{X}$ and gamma radiation. Radiat Prot Dosimetry, 15, 83-88.

Lloyd, D. C.; Edwards, A. A.; Moquet, J. E.; GuereroCarbajal, Y. C. (2000), The role of cytogenetics in early triage of radiation causalities. Appl Rad Isot., 52, 1107-1112.

Lushbaugh, C. C.; Hubner, K. F.; Fry, S. A. (1982), The impact of estimates of human radiation tolerance upon radiation emergency management. In The Control of Exposure of the Public to Ionizing Radiation in the Event of Accidental Attack. Proceedings of Symposium, 46-57. Washington DC. National Council on Radiation Protection and Measurements.

Ramalho, A. T.; Curado, M. P.; Natarajan, A. T. (1995), Lifespan of human lymphocytes estimated during a six year cytogenetic follow-up of individuals accidentally exposed in the 1987 radiological accident in Brazil. Mutat Res., 331, 47-54.

Roman, V. ; Fatome, M. ; Kolodie, H. (1997), Accidental acute irradiation. In: Court $L$ and Lallemand A (EDF eds) L'Homme Blessé, Paris, pp 105-106.

Rössner Jr. P.; Chvatalova, I. ; Schmuczerova, J. ; Milcova, A. ; Rössner, P. ; Sram, R. J. (2004), Comparison of p53 levels in lymphocytes and in blood plasma of nuclear power plant workers, Mutat Res., 556, 55-63.

Uma Devi, P.; Satish Rao, B. S.; Kamath, R. (1998), A method to score micronuclei in vivo using cytochalasin B-induced cytokinesis block. Mutat Res., 401, 33-37.
Received: August 26, 2008; Revised: September 11, 2008; Accepted: September 13, 2008 